\title{
Pulmonary Vascular Resistance and Direct Ventricular Interaction during Mechanical Ventilation in an Oleic Acid Induced Acute Lung Injury Model: A Review
}

\section{Jamie R. Mitchell}

Faculty of Medicine, Departments of Cardiac Sciences and Physiology \& Pharmacology, The Libin Cardiovascular Institute of Alberta, University of Calgary, Calgary, Alberta, Canada

\begin{abstract}
Treatment of patients with Acute Lung Injury (ALI) can be challenging. Mechanical ventilation is often required and can have significant adverse cardiovascular effects. Clinicians and research scientists have been able to utilize an experimental model of ALI/Acute Respiratory Distress Syndrome (ARDS) that can mimic much of the clinical sequelae. This model has provided the opportunity to systematically test best care practices and clarify the important cardiopulmonary interaction during mechanical ventilation. During mechanical ventilation with positive end-expiratory pressure, increased pulmonary vascular resistance (PVR) may adversely affect right ventricular (RV) function, and therefore, left ventricular (LV) function. Thus, increased resistance to RV output can result in decreased LV preload by series interaction, but importantly, also by direct ventricular interaction (DVI) (leftward septal shift). Therefore, if the increase in PVR can be minimized, for example, by volume loading or nitric oxide, the adverse effects of mechanical ventilation on cardiac function may be limited. This paper will review the possible cardiac consequences of elevated PVR through DVI during mechanical ventilation in ALI, and suggest potential benefits of reducing PVR.
\end{abstract}

Keywords: Acute respiratory distress syndrome; Nitric oxide; Cardiac function; Volume loading

The study of heart-lung interaction during mechanical ventilation in Acute Lung Injury (ALI) has been a focus in intensive care medicine for many years. However, some of the mechanisms by which mechanical ventilation adversely affects hemodynamics have not been clarified. It is clear that decreased $\mathrm{CO}$ is related, at least partially, to the effects of external constraint on ventricular filling [1,2]. However, during mechanical ventilation, increased pulmonary vascular resistance (PVR) may also adversely affect right ventricular (RV), and therefore, left ventricular (LV) function [3]. The PVR-lung volume relation is U-shaped so that resistance increases at greater lung volumes $[4,5]$. Large tidal volumes increase PVR and, for a given tidal volume, the increase in resistance is greater with positive end-expiratory pressure (PEEP) [6]. Increased resistance to RV output decreases LV preload not only by series interaction, but also by a leftward septal shift (direct ventricular interaction (DVI)) [7]. Therefore, if the increase in PVR can be minimized, for example, by volume loading $[7,8]$ or vasodilatation with nitric oxide (NO), the adverse effects of decreased RV systolic performance and reduced LV filling and output by DVI may be limited.

This paper reviews the important relationship between PVR and cardiac function during mechanical ventilation in ALI and suggests how NO, by reducing PVR, might improve cardiac function.

\section{Hemodynamic Effects of Acute Lung Injury and PEEP}

Oleic acid (OA)-induced ALI can also have hemodynamic consequences. Most studies have shown decreased CO [9-12] while a few reported no significant change [13-15]. Consistently demonstrated have been increases in PVR and mean pulmonary artery pressure $\left(\mathrm{mP}_{\mathrm{PA}}\right)$ [9-12,16-18]. Ehrhart et al. [19] using an isolated canine lung, attributed the increase in PVR to vascular obstruction presumably caused by large fatty acid globules which tend to lodge in and completely obstruct vessels. Increased alveolar volume with the application of PEEP may also mechanically compress pulmonary microvasculature with more pronounced resistance observed in a lower pressure system (Zone 2 conditions). Henning et al. [16] demonstrated significantly increased lung water content and PVR with $20 \mathrm{cmH}_{2} \mathrm{O}$ PEEP in OAinjured dog lungs. The increased lung water was attributed to increased microvascular hydrostatic pressure and impaired fluid drainage by pulmonary lymphatics caused by PEEP. However, in a pulmonary hypertensive model, a moderate level of PEEP could prove beneficial as unloading a saturated RV by redistributing blood to the periphery (decreasing venous return) could effectively reduce further edema formation that may have otherwise occurred due to elevated $\mathrm{P}_{\mathrm{PA}}$ 's. Hofman et al. [10] highlighted the importance of describing changes in PVR and consequent effects on both ventricular performance and lung function as PVR tends to decline over time in survivors but is maintained or further elevated in non-survivors. The importance of PVR is also supported by clinical studies that have shown improved cardiac function by pharmacological reduction in RV afterload (PVR) in Acute Respiratory Distress Syndrome (ARDS) [20,21]. Monitoring PVR at the bedside may prove to be a valuable diagnostic and prognostic tool that may be currently underutilized.

\section{Pulmonary Vascular Resistance and Direct Ventricular Interaction}

DVI can be viewed as the interaction of both ventricles via the septum. Because the heart is surrounded by the acutely non-distensible

*Corresponding author: Jamie Mitchell, PhD, Departments of Cardiac Sciences and Physiology \& Pharmacology, The Libin Cardiovascular Institute of Alberta, University of Calgary, GB37, Health Research Innovation Centre, 3280 Hospital Dr NW, Calgary, AB, T2N 4Z6, Canada, Tel: (403) 220-6066; Fax: (403) 210-9350; E-mail: jrmitche@ucalgary.ca

Received September 09, 2011; Accepted October 20, 2011; Published October 24, 2011

Citation: Mitchell JR (2011) Pulmonary Vascular Resistance and Direct Ventricular Interaction during Mechanical Ventilation in an Oleic Acid Induced Acute Lung Injury Model: A Review. J Aller Ther S4:001. doi:10.4172/2155-6121.S4-001

Copyright: (c) 2011 Mitchell JR. This is an open-access article distributed unde the terms of the Creative Commons Attribution License, which permits unrestricted use, distribution, and reproduction in any medium, provided the original author and source are credited. 
pericardium, changes in filling pressure of one ventricle may affect the other which, may alter output [22]. For example, when pulmonary artery pressure (RV afterload) is increased, RV end-diastolic pressure $\left(\mathrm{P}_{\text {RVED }}\right)$ can increase more than LV end-diastolic pressure $\left(\mathrm{P}_{\text {LVED }}\right)$ $[23,24]$. Since the end-diastolic septal position is determined by the transseptal pressure gradient $\left(\mathrm{P}_{\mathrm{LVED}}-\mathrm{P}_{\text {RVED }}=\mathrm{TSG}\right)[25,26]$, the resultant decrease in the TSG shifts the septum to the left. If the LV anteroposterior dimension does not change, [27-29] (which is often but not always true) the decrease in LV end-diastolic volume due to DVI is caused by the septal shift alone.

Previous studies of DVI during mechanical ventilation with steady-state measurements have yielded varying results. Fewell et al. [30] reported a decrease in both LV and RV end-diastolic volumes with increasing levels of PEEP. Conversely, Jardin et al. [3] published impressive data supporting the importance of this mechanism in cardiopulmonary interaction. They demonstrated a major leftward septal shift with increasing PEEP. However, the level of PEEP used in their study $\left(>20 \mathrm{cmH}_{2} \mathrm{O}\right)$ is seldom applied clinically. Cassidy et al. [27] using biplane cinefluorography for ventricular dimensional analysis, demonstrated a significant decrease in LV dimension with a concomitant increase in the RV dimension with increasing levels of PEEP (0-15 $\left.\mathrm{cmH}_{2} \mathrm{O}\right)$. Rankin et al. [31] have also demonstrated DVI associated with an increased PVR and RV afterload with increased intrathoracic pressure during a dynamic increase in airway opening pressure to $15 \mathrm{cmH}_{2} \mathrm{O}$. Presumably, as intrathoracic pressure is increased with PEEP, there is displacement of blood volume from the heart and lungs to the periphery. The increased impediment to $\mathrm{RV}$ filling would be additional to the direct lung compression in determining diastolic filling. The relationship between PEEP and PVR also needs to be considered. In general, increasing levels of PEEP will increase PVR [11,32-35]. When PVR is plotted against lung volume, a $\mathrm{U}$ - shaped relationship occurs with the nadir falling somewhere around the functional residual capacity value [4]. At lower lung volumes, the extra-alveolar vessels become compressed due to the elastic recoil forces of the lung parenchyma that cause the PVR to rise. As we normally do not utilize residual volume during respiration, fluctuations in PVR would normally fall somewhere on the post-nadir, ascending limb of the curve corresponding to changes in tidal volume. At these volumes, the extra-alveolar vessels can increase in diameter by radial traction while the alveolar vessels become compressed and, thus, contribute most to resistance.

\section{Hemodynamic Consequences of Increased Pulmonary Vascular Resistance}

With increased tracheal pressure/lung volume, there is potential for PVR to increase enough to have important hemodynamic consequences. Increased PVR, through its effect on the RV, may result in minimizing the decrease, or even increasing, RV end-diastolic volume despite the decrease in the overall size of the heart [12,36-39]. As a result, in addition to the effects on series interaction (the term "series interaction" is used to characterize the fact that the output of one ventricle affects filling, and therefore output, of the other), increased RV afterload also has the potential to limit LV filling (preload) and output by DVI (most often by a leftward septal shift) and even cause RV failure (acute cor pulmonale) during mechanical ventilation $[12,36,38,39]$. In fact, we have observed periods of acute RV failure when PVR was high in our animal work [7]. Furthermore, our results suggested that PVR was closely related to RV and LV performance and volume loading, by reducing PVR (by either recruitment of pulmonary vessels or increased transmural pressure in the pulmonary vasculature or both), improved RV and, therefore,
LV performance by series interaction and DVI (the TSG increased, which implies that rightward septal shift (DVI) also contributed to the increased LV preload). This was supported in a recent clinical study by Fougeres et al. [8] who assessed the hemodynamic effects of high PEEP with a subsequent increase in central blood volume in 21 mechanically ventilated ARDS patients. RV end-diastolic area (echocardiography) and PVR (flow-directed catheter) increased and cardiac index (CI) decreased with increased PEEP [5 \pm 1 (SD) to $13 \pm 4$ (SD) cmH2O], with 3 of 21 patients exhibiting acute cor pulmonale. Consistent with our observations, their findings also suggest that PEEP decreased CI by increasing RV afterload rather than by decreasing RV preload; increasing central blood volume by passive leg raising decreased PVR and the RV to LV end-diastolic area ratio (consistent with DVI) and increased the CI, which implies that reduced RV afterload contributed to the improved CO. Despite these findings, the contribution of PVR to heart-lung interaction by DVI during mechanical ventilation is not often considered.

\section{Nitric Oxide and Pulmonary Vascular Resistance}

Reducing PVR has the potential to improve cardiac function by several mechanisms resulting in improved RV systolic function and increased LV preload and output. However, a changing PVR and the subsequent effect on $\mathrm{CO}$ is difficult to define as the ordinate parameter (CO) is the denominator of the abscissa parameter (PVR), therefore the resultant hyperbolic relationship is predetermined. Patient studies have shown that the specific pulmonary vasodilatory effect of NO can be used to treat hypoxemia in ALI primarily by reducing PVR and improving the matching of ventilation with perfusion [40-43]. Hemodynamically, pulmonary arterial vasodilatation and the resultant reduction in PVR may decrease RV afterload thereby improving RV systolic function. This could have the effect of improving LV filling (series interaction

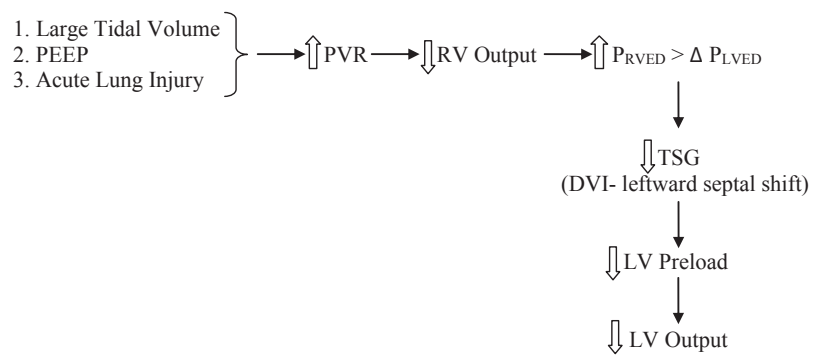

Figure 1A: Depicts different potential causes resulting in increased PVR. In creased RV afterload (PVR) may result in decreased RV output and a substantially increased $P_{1}$. The lack of an equal increase in $P_{\text {inf }}$ shifts the septum leftward resulting in deceased LV preload and output by DVI.

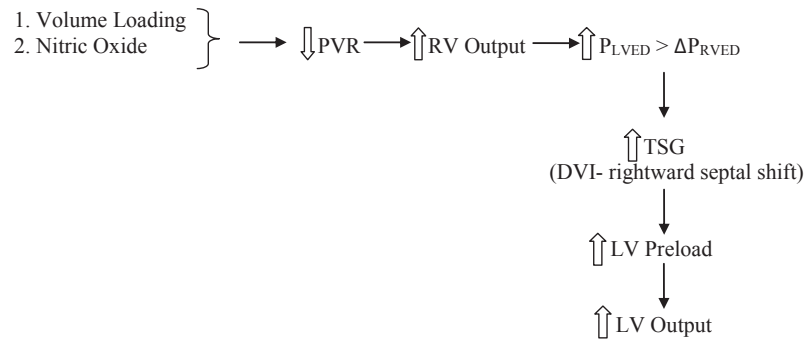

Figure 1B: Depicts the potential reversal of decreased LV output by interventions that tend to reduce PVR. PEEP, positive end-expiratory pressure; $P_{\mathrm{RV}}$ $R V$ end-diastolic pressure; $P_{\text {LVED }}$, LV end-diastolic pressure; TSG, transseptal pressure gradient; DVI, direct ventricular interaction. 
Citation: Mitchell JR (2011) Pulmonary Vascular Resistance and Direct Ventricular Interaction during Mechanical Ventilation in an Oleic Acid Induced Acute Lung Injury Model: A Review. J Aller Ther S4:001. doi:10.4172/2155-6121.S4-001

and improved DVI) and subsequent LV output by the Frank-Starling mechanism. Although many studies have shown a reduction in PVR with a focus on how NO can improve oxygenation, many have been constrained at providing a broad and in-depth hemodynamic analysis. Okamoto et al. [42] showed no change in CI after NO was administered (only $4 \mathrm{ppm}$ ) with increasing levels of $\operatorname{PEEP}\left(0,5\right.$ and $\left.10 \mathrm{cmH}_{2} \mathrm{O}\right)$ in 11 ARDS patients. Of note, the PVR index in their study only changed significantly at PEEP $0 \mathrm{~cm} \mathrm{H}_{2} \mathrm{O}$ after $\mathrm{NO}$ was administered. The lack of a reduced PVR index and improved CI may have been due to the low dose of NO used. It is our contention that if future NO experimental studies were to show significant reductions in PVR with concomitant improvements in cardiac function, it would highlight the importance of PVR in modulating ventricular performance.

\section{Conclusion}

The OA-induced ALI model is a well established tool that can be used to evaluate strategies in the management of ALI/ARDS patients during mechanical ventilation. Importantly, some data suggests that a reduction in PVR may be related to improved cardiac function and patient outcomes. Reduced PVR may be an important mechanism by which vasodilator therapy with NO improves cardiac function in ventilated patients with ARDS. We suggest the possibility that PVR may be a good target to help titrate NO to improve hemodynamics.

\section{References}

1. Qvist J, Pontoppidan H, Wilson RS, Lowenstein E, Laver MB (1975) Hemodynamic Responses to Mechanical Ventilation with PEEP: The Effect of Hypervolemia. Anesthesiology 42: 45-55.

2. Takata M, Robotham JL (1991) Ventricular external constraint by the lung and pericardium during positive end-expiratory pressure. Am Rev Resp Dis 143: 872-875

3. Jardin F, Farcot JC, Boisante L, Curien N, Margairaz A, et al. (1981) Influence of positive end-expiratory pressure on left ventricular performance. $\mathrm{N}$ Engl $\mathrm{J}$ Med 304: 387-392.

4. Miro AM (1994) Principles and practice of mechanical ventilation. In: Pinsky MR, editor. New York: McGraw-Hill.

5. West JB, Dollery CT, Naimark A (1964) Distribution of blood flow in isolated lung; relation to vascular and alveolar pressures. J Appl Physiol 19: 713-724

6. Cheifetz IM, Craig DM, Quick G, McGovern JJ, Cannon ML, et al. (1998) Increasing tidal volumes and pulmonary overdistention adversely affect pulmonary vascular mechanics and cardiac output in a pediatric swine model. Crit Care Med 26: 710-716

7. Mitchell JR, Doig CJ, Whitelaw WA, Tyberg JV, Belenkie I (2011) Volume loading reduces pulmonary vascular resistance in ventilated animals with acute lung injury: evaluation of RV afterload. Am J Physiol Regul Integr Comp Physiol 300: R763-R770.

8. Fougeres E, Teboul JL, Richard C, Osman D, Chemla D, et al. (2010) Hemodynamic impact of a positive end-expiratory pressure setting in acute respiratory syndrome: Importance of the volume status. Crit Care Med 38: 802-807.

9. Boiteau P, Ducas J, Schick U, Girling L, Prewitt RM (1986) Pulmonary vascular pressure-flow relationship in canine oleic acid pulmonary edema. Am J Physiol 251: 1163-1170.

10. Hofman WF, Ehrhart IC, Granger WM, Miller DA (1985) Sequential cardiopulmonary changes after oleic-acid injury in dogs. Crit Care Med 13: 22-27.

11. Scharf SM, Ingram RH Jr (1977) Effects of decreasing lung compliance with oleic acid on the cardiovascular response to PEEP. Am J Physiol I 233: H635-H641.

12. Zwissler B, Forst H, Messmer K (1990) Local and global function of the right ventricle in a canine model of pulmonary microembolism and oleic acid edema: influence of ventilation with PEEP. Anesthesiology 73: 964-975.

13. Ashbaugh DG, Uzawa T (1968) Respiratory and hemodynamic changes after injection of free fatty acids. J Surg Res 8: 417-423.

14. Kafi SA, Scillia P, Mélot C, Gevenois PA, Pagnamenta A, et al. (2002) Abnormal pulmonary vascular tone in canine oleic acid lung injury. Crit Care Med 30: 1565-1569.

15. Neumann P, Berglund JE, Anderson LG, Maripu E, Magnusson A, et al. (2000) Effects of inverse ratio ventilation and positive end-expiratory pressure in oleic acid-induced lung injury. Am J Respir Crit Care Med 161: 1537-1545.

16. Henning RJ, Heyman V, Alcover I, Romeo S (1986) Cardiopulmonary effects of oleic acid-induced pulmonary edema and mechanical ventilation. Anesth Analg 65: 925-932.

17. Schuster DP (1994) ARDS: Clinical lessons from the oleic acid model of acute lung injury. Am J Resp Crit Care Med 149: 245-260.

18. Schuster Dp, Trulock EP (1984) Correlation of changes in oxygenation, lung water and hemodynamics after oleic acid-induced acute lung injury in dogs. Crit Care Med 12: 1044-1048.

19. Ehrhart IC, Hofman WF (1981) Oleic acid dose-related edema in isolated canine lung perfused at constant pressure. J Appl Physiol 50: 1115-1120.

20. Fierobe L, Brunet F, Dhainaut JF, Monchi M, Belghith M, et al. (1995) Effect of Inhaled Nitric-Oxide on Right-Ventricular Function in Adult-RespiratoryDistress-Syndrome. Am J Respir Crit Care Med 151: 1414-1419.

21. Morelli A, Teboul JL, Maggiore SM, Vieillard-Baron A, Rocco M, et al. (2006) Effects of levosimendan on right ventricular afterload in patients with acute respiratory distress syndrome: A pilot study. Crit Care Med 34: 2287-2293.

22. Kroeker CA, Shrive NG, Belenkie I, Tyberg JV (2003) Pericardium modulates left and right ventricular stroke volumes to compensate for sudden changes in atrial volume. Am J Physiol Heart Circ Physiol 284: H2247-H2254.

23. Belenkie I, Dani R, Smith ER, Tyberg JV (1988) Ventricular interaction during experimental acute pulmonary embolism. Circulation 78: 761-768.

24. Belenkie I, Dani R, Smith ER, Tyberg JV (1989) Effects of volume loading during experimental acute pulmonary embolism. Circ 80: 178-188.

25. Kingma I, Tyberg JV, Smith ER (1983) Effects of diastolic transseptal pressure gradient on ventricular septal position and motion. Circulation 68: 1304-1314.

26. Thompson CR, Kingma I, MacDonald RP, Belenkie I, Tyberg JV, et al. (1987) Transseptal pressure gradient and diastolic ventricular septal motion in patients with mitral stenosis. Circulation 76: 974-980.

27. Cassidy SS, Mitchell JH, Johnson RL Jr (1982) Dimensional analysis of right and left ventricles during positive- pressure ventilation in dogs. Am J Physio 242: H549-H556.

28. Cassidy SS, Ramanathan M (1984) Dimensional analysis of the left ventricle during PEEP: relative septal and lateral wall displacements. Am J Physiol 246 792-805.

29. Mitchell JR, Whitelaw WA, Sas R, Smith ER, Tyberg JV, et al. (2005) RV Filling Modulates LV Function By Direct Ventricular Interaction During Mechanical Ventilation. Am J Physiol Heart Circ Physiol 289: H549-H557.

30. Fewell JE, Abendschein DR, Carlson CJ, Murray JF, Rapaport E (1980) Continuous positive-pressure ventilation decreases right and left ventricular end-diastolic volumes in the dog. Circ Res 46: 125-132.

31. Rankin JS, Olsen CO, Arentzen CE, Tyson GS, Maier G, et al. (1982) The effects of airway pressure on cardiac function in intact dogs and man Circulation 66: 108-120.

32. Jardin F, Delorme G, Hardy A Auvert B, Beauchet A et al. (1990) Reevaluation of hemodynamic consequences of positive pressure ventilation: emphasis on cyclic right ventricular afterloading by mechanical lung inflation. Anesthesiology 72: 966-970.

33. Jardin F, Farcot JC, Gueret P, Prost JF, Ozier Y, et al. (1983) Cyclic changes in arterial pulse during respiratory support. Circulation 2: 266-274.

34. Pinsky MR (1997) The hemodynamic consequences of mechanical ventilation:an evolving story. Intensive Care Med 23: 493-503.

35. Romand JA, Shi W, Pinsky MR (1995) Cardiopulmonary effects of positive pressure ventilation during acute lung injury. Chest 108: 1041-1048.

36. Jardin F, Gueret P, Dubourg O, Farcot JC, Margairaz A, et al (1985) Twodimensional echocardiographic evaluation of right ventricular size and contractility in acute respiratory failure. Crit Care Med 13: 952-956.

37. Scharf SM, Brown R (1982) Influence of the right ventricle on canine left ventricular function with PEEP. J Appl Physiol 52: 254-259. 
Citation: Mitchell JR (2011) Pulmonary Vascular Resistance and Direct Ventricular Interaction during Mechanical Ventilation in an Oleic Acid Induced Acute Lung Injury Model: A Review. J Aller Ther S4:001. doi:10.4172/2155-6121.S4-001

Page 4 of 4

38. Schmitt JM, Vieillard-Baron A, Augarde R, Prin S, Page B, et al. (2001) Positive end-expiratory pressure titration in acute respiratory distress syndrome patients: Impace on right ventricular outflow impedance evaluated by pulmonary artery doppler flow velocity measurements. Crit Care Med 29: 1154-1158.

39. Vieillard-Baron A, Jardin F (2003) Why protect the right ventricle in patients with acute respiratory distress syndrome? Curr Opin Crit Care 9: 15-21.

40. Hsu CW, Lee DL, Lin SL, Sun SF, Chang HW (2008) The initial response to inhaled nitric oxide treatment for intensive care unit patients with Acute Respiratory Distress Syndrome. Resp 75: 288-295.
41. Mehta S, MacDonald R, Hallett DC, Lapinsky SE, Aubin M, et al. (2003) Acute oxygenation response to inhaled nitric oxide when combined with high-frequency oscillatory ventilation in adults with acute respiratory distress syndrome. Crit Care Med 31: 383-389.

42. Okamoto K, Kukita I, Hamaguchi M, Motoyama T, Muranaka H, et al. (2000) Combined effects of inhaled nitric oxide and positive end-expiratory pressure during mechanical ventilation in acute respiratory distress syndrome. Artif Organs 24: 390-399.

43. Rossaint R, Falke KJ, Lopez F, Slama K, Pison U, et al. (1993) Inhaled nitric oxide for the adult respiratory distress syndrome. N Engl J Med 328: 399-405.

This article was originally published in a special issue, Lung Disorders/ Injury handled by Editor(s). Dr. Yutong Zhao, University of Pittsburgh, USA 